\title{
HOMOGENEIDAD Y HETEROGENEIDAD DEL SENTIDO: EL CASO DE COMO
}

\author{
Manuel Martf Sánchez \\ Universidad de Alcalá de Henares
}

\section{Consideraciones generales}

\subsection{Problematicidad de su estudio}

El lenguaje es un laberinto de caminos. Vienes de un lado y sabes donde andas; vienes de otro al mismo lugar y ya no lo sabes $(L$. Wittgenstein 1953: Investigaciones filosofficas, trad. esp., Barcelona: Crítica, 1988, parr. 203).

Estas palabras del pensador austriaco sobre esa kopacidad del lenguaje, su carácter elusivo, su resistencia a dejarse comprendern (Acero 1993: 60), resultan oportunas cuando se aplican al estudio de la partícula como. Los problemas que tal estudio plantea hacen que el analista, a veces, se encuentre perdido en medio de un laberinto del que no sabe salir (Cano 1995: 12), y que se complica aún más con la presencia del interrogativo-exclamativo cómo y la existencia frecuente de correlaciones en las que como se agrupa con otras partículas (asi como, tanto como, como que, como si, como para...), constituyendo, en ocasiones, lo que Trujillo llama un significado sintagmático, opuesto al singular (Trujillo 1990: 251).

Estos problemas comienzan con interrogantes del tipo: ¿que significado/s presenta?, ¿cuál es su función/es?, ¿de qué categoria/s gramaticalles y parte/s de 
la oración estamos hablando?, ¿cuál es la naturaleza de su antecedente y cuál la de la construcción que necesariamente encabeza? Y concluyen con preguntas mucho más fundamentales: ¿puede hablarse de una invariante semántica («valore semantico minimale», Ferrari 1995: 188), subyacente a sus distintas apariciones («fascio di valori pragmatici», Ferrari 1995: 188), lo que obliga a observar en sus construcciones un común denominador? Si este significado constante existe y se localiza en el saber propio del plano del sistema linguístico o, si preferimos, en la lengua-I, ¿cuál es la índole de este saber?, ¿cuál la relación que se da entre este conocimiento y el que da lugar en la actividad linguística al uso de este signo?

Siguiendo con el complejo asunto del significado constante, ¿qué rasgos son pertinentes en su identificación? Dado que, en un sentido praguense, numerosos ejemplos de construcciones con como se sitúan fuera de la gramática, dentro de lo pragmático y discursivo:

1a) Tenía la impresión de como que iba a dejarme (vid. 23e)

Ib) «Ella, como es lógico, hace el papel de carne» (La Codorniz Antología 1941-2, 235).

1c) Como defensa, Alkorta es el mejor.

¿en qué medida esos ragos distintivos pueden recoger todos estos usos? En todo caso, ¿a qué disciplina le compete su estudio?

Toda una maraña de asuntos, a los que superficialmente y de forma limitada nos asomaremos. Sin lugar a dudas, este artículo es un beneficiario directo de los grandes avances que se han producido últimamente en el estudio de la subordinación adverbial (Rojo \& Jiménez Juliá 1989, Narbona 1989 y 1990, Hernández Paricio 1992, Le Goffic 1993, López García 1994, Ferrari 1995...) y del propio como (Alcina \& Blecua 1975: 1056-1080, Trujillo 1990, Morera 1990, Moreno Ayora 1991, E. C. García 1992, Cano 1988 y 1995, Gutierrez Ordónez 1995...). Nuestra deuda es tan evidente que más de una vez nos hemos preguntado si merecía la pena intentar una nueva aproximación general a las construcciones de como. La respuesta afirmativa, que constituye este artículo, es un nuevo reconocimiento a la calidad de estos antecesores: sus aportaciones han abierto horizontes y suscitado problemas que exigen nuevas reflexiones.

\subsection{Los conectivos}

\subsubsection{Su importancia}

Las expresiones compuestas y complejas ( $A$. López García 1994), -a las que es corriente llamar oraciones compuestas y complejas (J.A. Martínez 
1994), o más tradicionalmente compuestas-, amén de las secuencias discursivas superiores, constituyen el modo principal por el que se crea el pensamiento desarrollado. Este necesita, por su parte, de estas estructuras para manifestar con exactitud esos contenidos en los que se relacionan, a veces de forma muy compleja, varias representaciones mentales. En semejante tarea, son decisivos los conectivos ${ }^{1}$, muchos de ellos encargados básicamente de la caracterización de la relación y, en cierta forma, de su existencia. Leibniz lo dijo muy bien con estas palabras, impregnadas de la vieja teoría racionalista del lenguaje como espejo de la mente:

Además de las palabras que sirven para designar las ideas, tenemos necesidad de aquellas que denotan la conexión de las ideas, proposiciones... Pero el espíritu, además de las partes de las proposiciones, liga también (...) proposiciones enteras, sirviéndose de palabras que expresan esta relación (...), y que son las que se llaman partículas; y en su acertado uso consiste principalmente el arte de bien hablar. A fin de que los razonamientos sean seguidos y metódicos, es preciso que haya términos que muestren la conexión, la restricción, la distinción, la oposición, el enfasis, etc... Es preciso observar sobre nuestro propio pensamiento para observar las formas que el espiritu afecta al discurrir. pues las particulas son otras tantas marcas de la acción del espíritu... el número de las significaciones excede mucho al de las partículas (cit. en E. Ramón Trives 1982: 33).

Tan importantes son que un criterio, poco seguido pero ciertamente bastante idiomático, es el estudio y clasificación de las expresiones compuestas y complejas de acuerdo con su conectivo; en vez de, como ha sido habitual, según ciertas categorías tomadas de la lógica (condición, causa, finalidad...). Los dos capítulos dedicados a la sintaxis compuesta en Alcina \& Blecua (1975) son un buen ejemplo.

R. Trujillo va todavía más lejos en el plano de la teoría. Firmemente convencido de que no existen estructuras sintáctico-semánticas propias de las expresiones compuestas y complejas (Trujillo 1988: 255-265), escribe:

Si nos atenemos a la estructura semántico-sintáctica de nuestra lengua, el estudio de la oración compuesta habrá de reducirse al de las

1 *Una entita linguistica, il cui valore consiste nell'indicare la natura - logica, illocutiva, di dispositio - della relazione che vige tra una coppia di connessi proposizionali, veicolati o veicolabili linguisticamente* (Ferrari 1995: 189). En 2.4. se verá que no es requisito indispensable la naturaleza proposicional de los elementos conectados. 
particulas conjuntivas, relativas o correlativas, y a su significado y capacidad de construcción (Trujillo 1988: 14).

\subsubsection{El significado básico, constante y unitario}

Trujillo, por tanto, propone centrar el estudio de las expresiones compuestas y complejas en el conectivo. Pero lo hace defendiendo al mismo tiempo, como es propio de la semántica estructural pero no sólo de ella (cf. Garrido Medina 1991: 582-3, Ferrari 1995: 200-1), que estos nexos poseen un significado idiomático, propio y constante. Precisamente, recordando la distinción coseriana entre gramática funcional y onomasiológica (Coseriu 1989: 12), sugiere dos maneras de organizar la enseñanza de una lengua: como una profundización en los significados idiomáticos de ésta, o como una manera de ver cómo ciertos conceptos universales y translinguísticos se expresan en cada lengua. Naturalmente, el profesor canario se decanta por el primer camino, que encuentra un importante apoyo en la variación que se da entre las lenguas:

2a) Las cosas son tan espirituales como los hombres/Les choses sont aussi spirituelles que les hommes.

2b) ¿Cómo va a hacer?/Comment allez-vous faire?

2c) ¡Qué feliz soy por ello!/Comme j'en suis hereux!

2d) El ha hablado como un hombre de Estado/He spoke like a statesman/He spoke as a statesman.

2e) Queria que permaneciera como originalmente se concibió/I wanted it to remain as originally conceived.

2f) Está diseñado para dar cuenta de cómo el lenguaje se usa/It is designed to account for how the language is used.

$2 \mathrm{~g}$ ) No es tan grande como su hermano/Sie ist nicht so gross wie ihr Bruder.

2h) Actúa como si fuera el rey de Francia/Er tut so, als ob er der König von Frankreich wäre.

Las consecuencias de esta decisión no ofrecen dudas. El gramático debe ir más allá de las generalizaciones del tipo como que para indicar causa pueden utilizarse porque, dado que, ya que, como, por (no) + infinitivo, que... Hay que entrar en las distinticiones, en lo específico de la lengua. Por ejemplo, no puede hablarse de sinonimia en (3a) y (3b):

3a) Lo hizo porque se lo ordené.

3b) Como se lo ordené, lo hizo. 
porque se lo ordené expresa el camino, la vía, que conduce, en este caso, del efecto a la causa, mientras que como se lo ordené alude al modo condicionante del efecto que sigue, como si dijeramos "en tal modo $\longrightarrow$ que lo hizo" (Trujillo 1990: 250)2.

Algo parecido habría que decir del supuesto de que cuando introduce prótasis condicionales (4a), similares a las encabezadas por si (4b):

4a) Cuando salgas, avisa.

4b) Si sales, avisa.

Sobre esta última equivalencia, E. Prieto observa con buen criterio diferencias entre las construcciones de cuando y las introducidas por si. Para él, la clave está en que

el primer papel condicional si, cuando efectivamente actúa como condicional, consiste en cambiar transitoriamente a un mundo posible, diferente del actual, en que poder hablar con sentido de cosas que incluso quizá no sucedan o no hayan sucedido (E. Prieto 1994: 512).

Hay que evitar, pues, la generalización que supone el agrupar una serie de construcciones diferentes en virtud de una categorización de carácter extralingüístico. Contra ello, la gramática funcional:

part du postulat qu'en principe $\longrightarrow$ 'est-à-dire, en dépit de l'eventuelle synonymie grammaticale et des syncrétismes toujours possibles-, dans una langue, il y a pour toute expression donnee un signifié unitaire déterminé (Coseriu 1989: 12).

\subsubsection{Los problemas del significado básico, constante y unitario}

Es muy interesante esta posición que compromete al investigador a rastrear en todas las apariciones de un signo esa invariante, ese significado básico, al que todas éstas deben reducirse. La semántica estructural de inspiración coseriana ha defendido excelentemente este presupuesto (Coseriu 1973: 204-212), que no es meramente metodológico, pues se justifica también epistemológica

2 Para las diferencias entre las construcciones causales con porque y como, vid. también Morera (1990: 689), Lopez García (1994: 223-4) y, para más detalles, E. C. García (1992: 612-9). 
si no podemos reducir las variantes a constantes o invariantes, no conoceremos más que hechos fisicos, pero sólo en cuanto tales, no bajo la forma del lenguaje (Trujillo 1976: 149).

y racionalmente:

ya que de otro modo no se explicaria por que los hablantes emplean una misma forma para muchísimas acepciones, a menudo muy diferentes, y no sólo para acepciones ya dadas y en contextos corrientes, sino también para acepciones «inéditas» y en contextos totalmente nuevos (Coseriu 1973: 205).

Sin embargo, la realidad linguística es demasiado compleja como para que pueda agotarla una sola teoría. Y a ésta no le faltan objeciones y dificultades. En primer lugar, está la índole de ese significado, realmente de difícil acceso a la objetividad científica como reconocen sus propios partidarios (Trujillo 1976: 149). En efecto, en opinión de Trujillo, y no parece que ande descaminado, este significado es indefinible e ininterpretable, «sólo está constituido por las condiciones que permiten intuir una palabra o una frase como realidad» (Trujillo 1988: 10). De este modo, «el significado de un signo es un "objeto único" $y$, por ello, aunque parezca paradójico, concreto" (Trujillo 1988: 10).

Naturalmente, existen otras concepciones del significado, a simple vista más precisas y determinadas desde una perspectiva cientifista y logicista (cfr. Moreno Cabrera 1994: cap. 10). No lo discutimos pero no nos detendremos en ellas. Por varias razones, entre otras porque en el fondo - pensamos- toda teoría que se ocupa de los significados, difícilmente puede huir de la esencial indefinibilidad de éste.

Ésta es la primera dificultad que presenta la teoría del significado unitario, una dificultad si queremos de principio. Pero éstas no concluyen aquí. En la realidad de los mensajes, los signos lingúísticos y muy especialmente los conectivos aparecen aquejados de los viejos fantasmas de la sinonimia y la polisemia. Veamos algún ejemplo referido a las partículas subordinantes.

Es un hecho que en ocasiones nos encontramos con sinonimias comunicativas como la que se da entre (5a) y (5b), y (5c) y (5d):

5a) ¿No ves que no oye?

5b) ¿No ves cómo no oye?

5c) ¿Cómo dices/haces/te atreves [eso/a eso]?

5d) ¿Por qué dices/haces/te atreves [eso/a eso]? 
Soslayando los deslindes que puede establecer el analista profesional predispuesto, lo cierto es que ambos pares de enunciados parecen responder -cada uno por su parte- a idénticas intenciones comunicativas.

También son llamativas las equivalencias a que dan lugar algunas estructuras ecuativas:

6a) Con cocochas es como más me gusta la merluza (Gutierrez Ordónez 1994: 364).

6b) Para que seas feliz es por lo que yo siempre me he sacrificado y ecuandicionales (Gutiérrez Ordóñez 1994):

7) Si lo hizo es porque quiso ${ }^{3}$.

Por otro lado, están las polisemias. Como las que originan ciertas construcciones encabezadas por para que (o proximas), que sirven para la expresión de contenidos ya no propiamente finales (Narbona 1990: 56-7, Alarcos 1994: 372, Sánchez López 1995. Los ejemplos que se citan provienen de Narbona y Alarcos):

9a) - Mándale el coche. - Sí; para que lo devuelva vacío.

9b) -No nos quiso recibir. - Para que te confies...

9c) La familia de Torquemada, o de San Eloy, para hablar con propiedad de mundana etiqueta, vivía apartada.

9d) Para el día que tenemos y lo perdidas que están las calles..., no trae ud. el calzado muy humedo.

9e) Para lo feas que son, han tenido suerte...

9f) -Pedro se ha hecho rico en dos años - ¡Para que después digan que no dejan dinero lo churros...!

Esta realidad de la sinonimia y de la polisemia en los nexos parece justificar el principio de la negociación postulado por J. Verschueren, en que se asienta su perspectiva pragmática en el estudio del uso lingüístico:

${ }^{3}$ Este ejemplo necesita explicacion, pues el si no aparece introduciendo lo que sería lógicamente la protasis (si lo quiso, lo hizo) sino su efecto. Con ello, nos encontrariamos como posible paráfrasis de esta frase la siguiente: "si se dio ese efecto (que 61 lo hiciera), la causa se encuentra en que él lo quiso". Cfr. este ejemplo con este otro aportado por S. Gutierrez (1986: 58): Si me voy a trabajar y obedezco órdenes es porque ud. y su madre y yo mismo, los tres, necesitamos comer (M. Puig). 
La negociación es lo que hace de la conversación un proceso dinámico y ésta es posible, desde el momento [sic] que distintos recursos linguísticos pueden satisfacer una necesidad comunicativa concreta $y$, al revés, un determinado recurso lingúístico puede poseer distintas funciones discursivas en situaciones, también, diferentes (L. Martf́n Rojo \& Meeuwis 1993: 90).

\subsubsection{La distinción de planos}

La respuesta a estas dificultades son de diverso orden. Con respecto a la existencia de polisemia, una solución para salvaguardar ese significado básico, unitario y constante es describir éste con el suficiente detalle (y, paradójicamente, con la necesaria generalidad), no limitándose sólo a alguna vertiente parcial (Coseriu 1990: 255). De este modo, se podrá

delimitar de acuerdo con la lengua una zona de variabilidad semántica en la que quepan y encuentren su justificación, en lo posible, todas las acepciones de esa forma comprobadas en el uso lingǘrstico ( $y$ también otras más, no comprobadas todavfas) (Coseriu 1973: 207).

Pero la defensa principal del significado básico, unitario y constante se encuentra en la afirmación de que su lugar se encuentra en la lengua funcional; mientras que el de las variantes, en el plano individual del hablar:

Si la polisemia existe, corresponde a la performance, es decir el empleo intencional de la identidad del significante para crear una situación lingürstica de ambigüedad, lo cual no es, en el fondo, más que un recurso expresivo o de estilo (Trujillo 1976: 237).

Mutatis mutandis, lo mismo viene a reconocer el generativismo chomskiano, cuyo ámbito es la lengua-I y no la lengua- $E$, conformada por los enunciados concretos. $\mathrm{O}$, incluso, $\mathrm{H}$. Parret, quien declara basándose en Wittgenstein y Merleau-Ponty:

La sémantique a comme objet le sens homogène, la pragmatique le sens hétérogène (...) La pragmatique en tant que telle considère le sens sous l'angle de ses hétérogeneités. C'est bien qui le distingue de la sémantique qui traite du sens sous l'angle de son homogéneité, toujours abstraite et reconstruite, le sémanticien se transformant nécessairement en observateur absolu (H. Parret 1991: 146). 


\subsubsection{Críticas}

Evidentemente, ni la teoría del significado constante ni los argumentos manejados en su defensa satisfacen a todo el mundo. Así, han surgido desde diversos frentes (filosofía, semántica, pragmática y psicolinguíística) voces en contra de la posibilidad de ese significado básico y constante, y de uno de sus fundamentos: la distinción entre los planos abstracto de la lengua y concreto de hablar.

Desde la filosofía de Wittgenstein, inaugurando una posición que presagia la llamada semántica de prototipos, se considera que es un error creer que a cada palabra le corresponda un significado constante. Éste depende o varía de acuerdo con las diferentes acciones verbales en que aparece. De ahí su famosa conclusión -aunque menos rotunda de lo que sugiere su archicitada versión abreviada- del párrafo 43 de las Investigaciones Filosóficas:

En una amplia clase de casos - aunque no en todos-en los que empleamos el término significado puede éste definirse así: el significado de una palabra es el uso que de ella se hace en el lenguajét.

Ésta es la posición defendida por T. Uribeetxebarria en un combativo, aunque no del todo convincente, libro. En él se sostiene una y otra vez que

La falta de limitacion y la capacidad de significarlo todo son dos cosas. Las palabras están abiertas a todas las posibilidades. No tienen invariantes ni variantes, sino usos comunicativos, $y$, a partir de éstos sus limitaciones no son significativas sino comunicativas (Uriboetxebarria 1992: 175).

Además, frente al argumento de Coseriu expuesto en 1.2.3 en defensa de la realidad de la invariante semántica, contesta:

Las variantes no tienen ningún tipo de unidad que se derive de una invariable hipotética; las palabras lo son por la forma, y es ésta la que da unidad a sus usos: siempre se trata de la misma palabra a pesar de la infinita variedad de sus usos (Uribeetxebarria 1992: 100).

Tan explícita declaración de que sólo el significante es lo que proporciona unidad a la palabra coincide perfectamente con su defensa de la polisemia (cfr. Trujillo 1976: 237).

- Cfr. «La oración ha de ser vista como un instrumento, y su sentido como su empleo» (Investigaciones Filosóficas: párrafo 421). 
En lo que refiere a la pragmática, se insịste en que el significado no depende exclusivamente de lo que ellos llaman, a la manera chomskiana, gramática:

No creo que el significado se halle esencialmente ligado a la convención. A lo que se halla esencialmente ligado es a alguna manera de fijar lo que significan las oraciones: de hecho, la convención es una de esas maneras, pero no es la única (P. Grice 1989: Studies in the Way of Words, 298, apud Acero 1993: 57).

En efecto, en la pragmática que se mueve en el marco de la teoria de la relevancia, los efectos de sentido que se obtienen a partir de una forma lingüística, en este caso un conectivo, se explican porque

Il connetivo possiede un valore minimale (logico) e un insieme di istruzioni pragmatiche algoritmicamente organizzate: il suo significato effecttivo coincide con l'ultima istruzione attivata, vale a dire con l'istruzione che ne rende pertinente l'impiego (Ferrari 1995: 39).

Esto es, se opta para explicar los distintos valores recurriendo al tratamiento procedimental (procedurale), que explica el sentido de un signo acudiendo no sólo al significado básico sino también a los procesos generales del razonamiento humano, que, partiendo de ese significado, lo enriquecen con la información contextual hasta llegar a la información más pertinente (V. Escandell 1993: 185-197. Cf. Garrido Medina 1991). E.C. García (1992: 615) discurre por este mismo camino para explicar la interpretación causal que, a veces, adquiere, como.

Seguramente, los problemas principales de la teoría del significado básico, constante y unitario provienen de los ataques contra la viabilidad de la distinción entre el plano de la lengua y el de su uso. Para Wittgenstein, el primero es una entelequia:

Fuera del uso un signo en sí está muerto. El signo vive únicamente en el uso... El uso es como su respiración (Investigaciones Filosóficas: párr. 432).

Esta posición, que puede sorprender, dado que la teoría de los planos del hablar está muy arraigada en la tradición lingúística occidental, encuentra un importante valimiento, más experimental, por parte de la psicología del lenguaje. En el seno de ella existen voces cualificadas que abogan por la inexistencia de un conocimiento del lenguaje autónomo e independiente de sus funciones sociales (comunicativas) y cognitivas (perceptivas o conceptuales) (Cfr. 
Belinchón, Igoa \& Rivière 1992: 247). O se pronuncian a favor de la ausencia de fronteras entre este conocimiento y el que implica el uso linguístico (Cfr. Belinchón, Igoa \& Rivière 1992: 253-8). Si no hay un conocimiento autónomo del lenguaje, la existencia del significado básico constante y unitario se torna casi imposible.

En resumen, esta breve incursión en el asunto del significado constante nos ha conducido, una vez más, a la conclusión de la discordia de las opiniones y, una vez más, a la exigencia de -si se quiere de verdad hablar en seriomarchar hacia los fenómenos. Es lo que nos disponemos a hacer con las construcciones de como.

\section{El CASO DE COMO}

\subsection{La defensa del como básico, constante y unitario}

Frente posturas más clásicas dentro de la tradición más reciente (M. Seco, Alcina \& Blecua, Moreno Ayora, S. Gutiérrez, R. Cano), que hablan de varios como semántica y categorialmente (adverbio relativo, conjunción subordinante, preposición, prefijo); estudiosos como R. Trujillo (1990) y su destacado discípulo M. Morera (1990), en nuestra gramática, o P. Le Goffic (1993» 394$399,482-4$ ), en la francesa, han defendido la existencia de un único como, proadverbio relativo, con un significado básico, presente en todas las apariciones de como. Aunque con menos explicitud, ésta también ha sido la postura de A. Alonsos y de E.C. García (1992: 600, 619).

Estudiemos esta segunda posibilidad y consideremos sus implicaciones. Al hilo de todo ello, irán surgiendo los inconvenientes. Al final, estaremos en mejor condición para evaluar la hipótesis del significado básico, constante y unitario aplicada a como. Anticipamos ya que nuestras conclusiones van a ser un tanto decepcionantes, pero no podemos ir más lejos dada la escasa falsabilidad de esta teoría y de su crítica.

Sin más dilación y siguiendo lo que sus defensores propugnan, conformaremos con las siguientes notas lo que podría ser ese significado de como, esto es, su función de lengua:

3 Para quien todas las posibilidades de como arrancan del valor modal y «no son radios de un círculo que se alejen incesantemente del centro, sino que permanecen proximas y movibles, como hojas de una misma rama, en continuo contacto, y entrecruzamiento de significaciones» (apud Narbona 1990: 70). 
A) Es un signo mostrativo, cuyo referente lo recibe de un elemento modal que aparece - de forma explícita u omitida - en el primer constituyente del enunciado, y que podría representarse por la archiforma ASf. Esta modalidad transferida justifica que categorialmente se hable de como como adverbio.

B) Es también un nexo - Le Goffic (1993: 392) se refiere a él como adverbio conector-, pues sirve para poner en contacto dos componentes del enunciado. Volviendo a Le Goffic (1993: 392), nos parece especialmente feliz la metáfora de "clavija" (cheville), tomada de Damourette y Pichon, para referirse a esta actuación.

C) Esta misión conectiva la consigue gracias a su condición de signo mostrativo. Como en el segundo constituyente reproduce su antecedente pero añadiendo, además, las notas de "identidad":

10a) Lo dejó de la manera como lo había visto hacer.

10b) Consideró a Juan como un hombre de importancia o "analogía". o «analogía»:

11a) Iba como un libro desencuadernado.

11b) Andaba siempre como si llevara zapatos pequeños.

Por medio de ambas notas, como agrupa el valor modal con el comparativo. Este último valor se hace más nítido cuando el antecedente de como aparece cuantificado (es tan alto como Pedro) o él mismo es un cuantificador (habla tanto como su hermano) 6 .

D) Estos valores relacionales de "identidad" (equivalente a la función "es") o "analogía" (parafraseable por la función "parece") justifican la presencia de ese segundo constituyente introducido por como.

E) M. Morera aglutina esta triple condición de como: a) signo mostrativo que representa modalidad, b) expresión de las relaciones comparativas de "identidad" y "analogía", y c) conectivo, bajo la forma DE(L) MODO QUE.

- Trujillo (1990: 261) menciona que el valor comparativo een el terreno de la realidad difícilmente se diferencia del de modo» (cf. Halliday 1985/1994: 234). Refiriéndose al latín, Sánchez Salor (1993: 252) sencillamente los une. No será este el único caso de confluencia de lo modal con otros contenidos (vid. supra 2.2.). Desde una perspectiva comunicativa, las cosas se ven de modo diferente: «aunque el transpositor de las comparativas y de las relativas modales sea el mismo, se trata de dos construcciones diferentes, ya que en la comparativa el miembro-fondo está orientado hacia el hablante, como dado, y en las relativas de modo dicho miembro-fondo está orientado hacia el oyente, al igual que en las demás relativas, como no dado» (Á. López 1994: 464). 
F) De acuerdo con esta interpretación, la construcción de como puede verse como una complementación comparativa del antecedente modal. Precisamente, la correferencialidad entre este antecedente modal y el como, con la consiguiente previsibilidad del primero, es la razón de que el primero desaparezca con tanta frecuencia y factor decisivo en que la complementación de como adquiera frecuentemente el carácter - en las paráfrasis que obliga esta teoría- de una aposición irrestricta. Tal eventualidad se da mucho menos en los casos en que el antecedente se halla presente:

12a) Lo hizo así como dijiste

aunque no siempre existe esta correlación:

12b) Lo hizo así, como dijiste.

\subsection{La necesidad del antecedente}

De acuerdo con la teoría expuesta, como es un signo mostrativo que necesita la existencia de un antecedente, de carácter modal, al que referirse. A veces, este antecedente aparece como consecuente, lo que se vuelve en contra de la interpretación de la construcción de como como desarrollo del componente modal de la principal:

13a) Jugó como tú quieres, con disciplina.

13b) Porque como la corona ciñe la cabeza, así la fe ciñe a nuestro entendimiento (Nierenberg: Epistolario, apud Cano 1995: 47)?

$Y$, a veces, hay que buscarlo fuera del mismo enunciado oracional de como:

14) Ése es un erotismo convencional, pobre de emociones, que no alcanza a satisfacer la necesidad profunda (...). Como el del cine americano, donde nada es normal... (R. Torres: «La polaroid», El Mundo, 16/3/1996).

7 En ejemplos como: Coma me lo dijiste, así lo he hecho, según A. Narbona (1990: 70) el correlativo de como «puede actuar como elemento que corrobora o confirma lo introducido por comow. 
Dada esta confluencia redundante de los dos elementos correferenciales, el primero de ellos, el antecedente de como se omite con mucha frecuencia ${ }^{8}$. Es más, a menudo tal ausencia es imprescindible:

15a) Hubo episodios de tristes recuerdos *así como el rey de Portugal.

15b) Como en todas las cosas, hay que buscar aquí el equilibrio.

Tal omisión del antecedente es origen de problemas, pues la riqueza y variedad de construcciones en que aparece como, algunas muy alejadas ya del significado comparativo-modal y relevantemente antepuestas (en su mayoría) a la oración principal, se vinculan al «perder [como] su capacidad pronominal de aludir a un antecedente» (Alcina \& Blecua 1975: 1056).

Para Trujillo y Morera, tal hecho, que recuerda el origen adverbial y pronominal de muchas conjunciones, no reviste mayor dificultad. De acuerdo con el primero, siguiendo una vez más a Bello, el antecedente puede ser "preciso" (en la manera como se expresa) o "global", «es decir, un antecedente "envuelto", cuyo contenido pertenece al mismo como, sin que se pueda separar de él» (Trujillo 1990: 253). No echemos en saco roto esta realista indicación de Trujillo para los casos de antecedente "global y envuelto", que matiza los posibles juicios desfavorables de forzamiento de la realidad que pueden verterse sobre su teoría (vid. supra 3 ).

Expreso u omitido, preciso o global y envuelto, el mostrativo como requiere un antecedente que el análisis deberá reconstruir. Esta doctrina resulta plausible en ejemplos como:

16) Lo hizo como le dijiste.

donde es muy cómodo postular un antecedente omitido que representamos por medio de ASf; o al menos sostener que existe algo así como «una inferencia modal del texto precedente, en la que como es principio y fin de la relación que se establece con el consecuente» (Trujillo 1990: 255). Lo malo es cuando se abandonan estos ejemplos. Entonces, la solución ya resulta más difícil y más factible alejarse del contenido básico propuesto.

En:

17a) «Como perdía en el juego con frecuencia tenía muchos apuros» (Pío Baroja: El árbol de la ciencia).

- Esta característica de como la comparte con cuando, frente a donde, que «puede llevar antecedente de significado léxico variado» (Alarcos Llorach 1994: 102). No obstante, no conviene extremar este punto (Cano 1995: 92). 
puede parafrasearse de forma semejante a "tenía muchos apuros en estas circunstancias [=ASI]]", donde ASI equivale a "perdía en el juego con frecuencia". De este modo, justificaríamos la presencia de como y mantendríamos la razón de la teoría de la invariante. Sin embargo, lo que comunicativamente el hablante parece estar indicando es el porqué, la causa de que el sujeto tuviera muchos apuros. Si bien, y no podemos contradecimos con lo afirmado en 1.2.2., tal información no supone que 17a) sea equivalente a:

17b) Tenia muchos apuros porque perdía en el juego con frecuencia. como muestra la coocurrencia de porque y como causal en un mismo enunciado:

17c) He venido temprano porque como siempre está malo

También es difícil encontrar el antecedente modal, y lo que ello supone, en este ejemplo de como condicional:

18) Como llegues tarde otra vez, no te espero.

Para obtenerlo hay que recurrir a los siguientes pasos: "No te espero ASf [=si sucede esta eventualidad]. Así = llegar tarde". Tal solución es posible, pero el hablante y el oyente parecen ir por otros derroteros y lo que perciben es una condición.

En:

19) [Esa tesis] es tanto casi como proponer un cambio radical de civilización habría que recurrir a algo así como: "esa tesis casi supone ASI [tanto], ASÍ [co$m o$ ] es análogo a un cambio radical de civilización". El análisis no es disparatado y permite una justificación genética de la construcción; pero a nadie se le oculta su carácter forzado y su desconocimiento del sentido comparativo-intensivo de esta construcción.

Respecto a ejemplos -que deben diferenciarse de 16)- del tipo:

20a) Hicieron como les dijo.

20b) Sea como mandares.

R. Cano (1995: 39) observa la pérdida de la nota modal y la conversión de como en un relativo más o menos neutro, equivalente a "lo que", con el que se re- 
coge toda la oración principal o, por lo menos, su predicado, pero sin aludir ya a ningún modo. A nuestro parecer, se trata de enunciados claramente ambiguos y que, en parte, se explican por la relación que se da entre el complemento directo y el modal (Á. López García 1994: 465), sin que todo ello suponga una dificultad insalvable para el mantenimiento del significado básico propuesto de como, con la consiguiente necesidad de la presencia de un antecedente modal omitido.

Por supuesto, en cuanto a esto último, toda discusión resulta estéril si no se define claramente qué se entiende por antecedente de naturaleza modal, y a ello todos nos atenemos. Seguidamente, se tratará con más calma esta cuestión capital.

No muy lejanos a 20a) y 20b) se encuentran estos ejemplos de cómo anunciativo:

21a) Mira cómo Pedro se encarga de todo.

21b) Le contó cómo lo había conseguido.

variante del que completivo y cuya misión es «garantir la vérite de $p$., de souligner la factivité de OP, ce que ne fait pas le relateur que qui "suspend la valeur de vérité de p", celle-ci se trouvant exprimée dans OP» (Vanderlynden 1992/4: 437). El problema del cómo anunciativo es su distinción del cómo interrogativo que se da en ciertas estructuras y que sí se asocia a contenidos modales. Estas dificultades de distinción se manifiestan claramente en enunciados ambiguos como:

22) Está ud. hablando de cómo las canciones se han convertido en objeto de consumo (Vanderlynden 1992/4: 438).

\subsection{Antecedente y Consecuente}

\subsubsection{La naturaleza modal del antecedente}

Hablando de la naturaleza del antecedente de como y de él mismo, están utilizándose sin ninguna precisión los términos valor/contenido/información modal y modalidad. Y no podemos seguir más así. Para poder argumentar en favor o en contra de esta teoria del significado unitario, que encuentra en como siempre un signo mostrativo en constante remisión a un antecedente modal, habrá que determinar qué se entiende por esta etiqueta. Tal examen nos situará ante su polisemia y ante la compleja realidad de los actos verbales, donde se cruzan y entrecruzan diversos niveles estructurales. 


\subsubsection{Construcciones de como en el nivel sintáctico}

En los ejemplos más sencillos, el antecedente se sitúa dentro de la predicación, del dictum que dirían otros, como complemento adnominal ${ }^{9}$, atributo, predicativo y complemento circunstancial de modo (interno y externo) ${ }^{10}, \mathrm{pu}$ diéndose interpretar como y sus segmentos como un desarrollo de él:

23d) Quiero expresar mi sorpresa de que un asunto tan importante como éste se olvide.

23e) Está como enfermo.

23g) María Cristina gobernó como regente.

23h) El Madrid jugó como siempre.

23i) Estas palabras, como todas las demás, no son ambiguas.

23j) Las leyendas, como los falsos cronicones, son, a veces, tan auténticos como la historia (D. Álvarez: «Duquesa de Alba», La Revista 17/3/96).

En todos estos casos, el análisis puede mantenerse en el nivel sintáctico (en un sentido amplio), conformado por la realización entre el núcleo predicativo con sus participantes y circunstantes. Tampoco la justificación del contenido modal entraña un gran problema: la construcción de como se ubica en complementaciones acerca del modo de ser/estar/gobernar/jugar/no ser ambiguo/ser tan auténtico. Conviene reparar en que esta complementación modal trasciende la complementación verbal -en la que podrían incluirse los atributos- También es posible la nominal (23a, c y d), en la que como se aproxima al relativo que.

- A veces, esta complementación nominal es de carácter interno, ya que se encuentra encerrada en las propiedades del propio sustantivo:

23a) Un hombre como Pedro no puede hacer esto.

23b) Del evangelio, como buena nueva de Dios, surge una nueva humanidad para el hombre (O. Glez. de Cardenal 1995: Rafz de esperanza, 16).

23c) Intentando (...) conseguir la carda de IU, como la que facilito (...) el infarto de Julio Anguita (P. Sebastián: El Mundo, 21/2/96).

10 Para el complemento circunstancial de modo, vid. Masia Canuto (1994: 70-78), que propone una clasificación de los complementos circunstanciales de modo de naturaleza semántica, que no seguimos; para la distinción entre circunstancias internos y externos, Martí Sánchez (1993). Ambos contienen bibliografía reciente sobre los circunstanciales. En 23j), la primera aparción de como es interpretable como un caso de complemento extemo, que afecta a toda la estructura oracional que comenta, al igual que 23i); la segunda se halla más integrada y es de ámbito de incidencia más restringido, se limita al predicado. 
Sin embargo, dentro de este mismo nivel sintáctico, sabemos que hay ejemplos difícilmente asimilables a ese contenido modal, entendido como "una manera, un modo de SER, de HACER algo". Ahí están los ejemplos 20a y b) ya comentados. Ahí está 17a), con la paráfrasis propuesta se solventaba (para los que creen en su existencia) la cuestión de su antecedente, pero el contenido modal —pese al archiantecedente ASÍ o que pueda introducirse en lugar de en esas circunstancias, de este modo- resultaba bastante menos nítido.

Llegamos aquí a un punto clave. En la lengua, el sustantivo modo, como y sus conexos así, del mismo modo o los adverbios en -mente (Le Goffic 1993: 469) tienen un ámbito designativo que sobrepasa -en un hablar más precisola "forma, manera, modo particular de SER o de HACER algo". Este hecho habría que ponerlo en relación con las indistinciones ya referidas entre complemento modal y directo (infra 2.2. y n. 12), modo y cantidad (infra n. 6). Con la frecuencia con la que el interrogativo cómo selecciona respuestas claramente, al menos en apariencia, no modales:

24a) ¿Cómo consiguió moverlo?

- Con el gato.

24b) ¿Cómo llegor?

- Por la autopista.

24c) ¿Cómo has dicho?

- Que no me da la gana".

o remite a antecedentes suspendidos (Morera 1990: 685-6), que pocos podrían interpretar como modales (Moreno Ayora 1991: 78-90, Cano 1995: 16-32):

24c) Les contó cómo lo habían hecho.

24d) ¿Cómo te quejas tan amargamente?

24e) ¿A cómo está el aceite de oliva?

24f) ¿Cómo de guapa es Edith?'12

"S. Gutiérrez Ordóñez (1995) ve en este uso a cómo en el papel de sustituto nominal de referencia de dicto, lo que le distingue del qué de preguntas como ¿qué has dicho?, ligado a la referencia de re. Esto es verdad, pero también —añadimos- que este empleo de como responde a la indistinción, a veces, entre los complementos modales y directos, a que se acaba de aludir.

12 En 24c) aparece un enunciado ambiguo semejante al que aparecía en 22). 23d) cuenta con un cómo contextualmente equivalente al causal por qué. Sin embargo, cabe entenderlo también como un elemento modal, que hay que situar en el plano de la enunciación y de la modalidad oracional. Tal análisis podría expresarse por medio de esta paráfrasis: "¿En qué modo realizas la acción de quejarte con tanta amargura?". Claro, la relación entre el modo de este cómo y el que se da en me quejo como quiero pareçe puramente semasiológica. Respecto a esta relación entre cómo y por 
En este terreno de la complementación sintáctica modal, la lengua parte de un concepto vago y muy amplio, como muestran estos testimonios directos $u$ otros más indirectos. Por ejemplo, la facilidad con que tantos alumnos ven complementos circunstanciales de modo que exceden los que cabrian en una definición estricta. Tal proceder intuitivo se refleja en algunas clasificaciones recientes de los circunstanciales (L. Gosselin 1990: 33-4), de los usos preposicionales (Pottier 1962: 124-7; P. Sancho 1994) o de las determinaciones verbales, incluidas las tradicionales subordinadas. Aquí estamos refiriéndonos a la clasificación propuesta, siguiendo a Tesnière, por Sánchez Salor (1993), que distingue los planos espacial, temporal y nocional. En este último entran completivas, causales, condicionales, concesivas, finales, consecutivas y comparativo-modales.

\subsubsection{Construcciones de como en la enunciación y modalidad oracional}

Pero los problemas de como y su modalidad, ya de por sí importantes, no concluyen aquí. Como aparece en usos que ya no pertenecen al nivel sintáctico, o no lo hacen de forma completa:

25a) Esta nueva opcion representa, como se ve, un valioso aporte a la economía.

25b) Como decía mi abuelo, el que no se fía no es de fiar.

25c) Haré, como introducción, un breve repaso del status quaestionis.

25d) «Srta. Greta: Ahí está el hombre que viene a morirse por ud., como de costumbre» (La Codorniz Antología 1941-4, 236).

25e) Como padre tuyo, te aconsejo ese camino.

En estas muestras, la construcción de como se localiza en el nivel de la enunciación y de la modalidad oracional. Avalan este juicio su aparición como inciso o, en algún caso, su anteposición, actuando, pues, como tema topical (Halliday 1985/94: 53), fiel reflejo de que se halla bajo la acción de lo pragmático-discursivo más que de lo gramatical.

qué, y el análisis propuesto, es útil lo que se dice en Kuno \& Takami (1993: 75-125), con argumentos sintacticos y funcionales. 24e) ofrece algo frecuente en las construcciones de como: la superposición de dos estructuras. “CCómo está el aceite de oliva? ¿a cuánto está el aceite de oliva?”. Esta superposición se explica bastante bien por la conexión existente entre ambas, aspecto que se ve todavía más claro cuando se contemplan sus dos enunciativas correspondientes: el aceite de 0 . está caro (¿cómo?), el aceite de o. está a 700 ptas. $\Lambda$. (¿cuánto?). El alejamiento del modo para situarse en la cantidad es evidente en 24f), donde cómo epregunta por el grado en que la propiedad especificada por el adjetivo se aplica a la Frase Nominal» (E. Torrego 1994: 265). 
Pese a la coincidencia teminológica, esta modalidad - tan ligada a lo textual (Halliday 1985/1994: 42) y tan variada (Maingueneau 1976: 125-134, Ferrari 1995: 98-100, C. Fuentes 1996: 27-42)— se refiere a una realidad diferente a la de los complementos modales que acaban de verse, aunque comparte bastante frecuentemente con éstos el carácter de comentario, de calificación realizado por el hablante. En la modalidad oracional, sobre el enunciado; en los complementos modales, sobre un núcleo de la estructura predicativa. Podría decirse que, en éstos, la construcción de como constituye un modo de primer grado; en los adscribibles a la modalidad oracional, un modo segundo.

Como puede pensarse, estos ejemplos de como claramente vinculados a la enunciación y la modalidad oracional son poco cómodos para la teoría unitaria del significado constante, que parece funcionar mejor en la sintaxis. Estos como ya no designan un "modo de SER o HACER" dentro de la estructura predicativa; por tanto, su paráfrasis no coincide con los interpretables sintácticamente, por tanto, la visión unitaria entra en crisis.

\subsubsection{Dificultades de distinción}

Así pues, en un intento de ordenación y en relación con la modalidad, cabría hablar de dos como: los sintácticos y los pragmáticos-discursivos, operantes en el plano de la enunciación y la modalidad. Este deslinde es útil como orientación, pero no puede inducir al error de creer que el plano de la sintaxis y el de lo pragmático-discursivo se hallan claramente delimitados. No lo están ni siquiera en la mente de los teóricos. Volvamos a dos enunciados ya aparecidos:

1a) Tenía la impresión de como que iba a dejarme.

23e) Está como enfermo.

Siguiendo rígidamente la teoría unitaria, pueden interpretarse sintácticamente, como desarrollos de un complemento nominal («Tenía una impresión ASf́. ASÍ análogo a [=como] que iba a dejarme») o un atributo («está ASI, ASf́ análogo a [=como] a enfermo») implícitos. Sin embargo, también es posible considerar que, en estos dos enunciados, como es un operador modal, superpuesto a las estructuras básicas tenía la impresión de que iba a dejarme; está enfermo. Esta última posibilidad no tiene nada de particular para el analista de como, quien sabe que la presencia del conectivo va acompañada de un juicio, de una estimación del hablante.

Algo más complejo es el análisis de: 
26a) Meditaste este libro como una respuesta a tus problemas.

26b) Joven, medita este libro como una respuesta a tus problemas.

En 26a) aparentemente no hay mucho que decir: como una respuesta a tus problemas es un complemento modal, que toma su referencia del antecedente implícito ASf. Sin embargo, un examen más cuidadoso hace ver que ese modo no coincide con el que, por ejemplo, manifiesta cuidadosamente en este enunciado, donde se mantiene la misma complementación de como:

26c) Meditaste este libro cuidadosamente como una respuesta a tus problemas.

Esto induce a pensar que como transmite un tipo de información diferente a la del prototípico modal cuidadosamente. En concreto, creemos percibir que alude a una manera de meditar - de ahí que pueda seguirse hablando de modalidad-, que no sólo acompaña a esta acción en su desarrollo, como cuidadosamente, sino que también alude al resultado final que en 26b), dominado por el modo imperativo, se ve como deseable. Precisamente, en este 26b) se observa asimismo, lo que también lo vincularía a la enunciación y modalidad oracional, una actuación del hablante orientada a la buena fortuna de la acción propuesta al oyente. En 26a), fuera ya del modo imperativo, este rasgo no se da y la intervención del hablante se esconde tras la descripción del hecho.

En lo que respecta a los casos adscribibles al plano pragmático-discursivo, no parecen tan desligados de la estructura sintáctica como podría pensarse. No lo están porque el antecedente que puede catalizarse parece hallarse dentro de esa predicación que hemos entendido como la sede del nivel sintáctico. Por ejemplo, en:

25d) «Srta. Greta: Ahí está el hombre que viene a morirse por ud., como de costumbrem (La Codorniz Antología 1941-4, 236).

25e) Como padre tuyo, te aconsejo ese camino.

como remite a un oculto ASÍ que se halla unido junto al verbo: "Ahí está el hombre que viene a morirse por ud. ASI [= como de costumbre]"; "te aconsejo ese camino ASI [ = como padre]".

De este modo, en estas construcciones como mantiene sus rasgos fundamentales: su carácter relacional con las notas de "identidad" o "analogía", y su dependencia de un contenido modal entendido de forma amplia, como lo interpreta la lengua. 


\subsection{La naturaleza categorial del consecuente}

La hipotética unidad de como reposa en su unitariedad semántica, pero también en una cierta unidad categorial. De esta forma, es incompatible la unitariedad semántica con la postulación de un como adverbial relativo y un como conjuntivo. Sin embargo, es factible mantener la unitariedad semántica de nuestro conectivo con la distinción de un como preposicional y uno relativoadverbial. Este hecho solo afectaría a la condición proposicional o no del segmento introducido por como. Al igual que sucede con otros relacionantes (cuando, según, donde...), como aparece encabezando sintagmas o palabras. En ocasiones, el recurso regularizador de la elipsis es posible:

27) Tenía los ojos azules como un mar en calma ${ }^{13}$.

Otras veces, la elipsis es imprescindible para dar cuenta del contenido de la secuencia:

28a) Pedro, como Juan, terminó a malas.

28b) Todo el mundo habla de la boda de la infanta como de los GAL.

28c) Es tan alta como la Torre del Oro.

Pero hay ejemplos en que no cabe pensar en elipsis ya que no hay posibilidad de una catálisis del verbo, que daría lugar a una secuencia agramatical o a una alteración del contenido:

29a) Ingres6 como cadete en la Academia de Marín.

29b) Había como unas veinte personas.

29c) Habla como portavoz (cf. habla como niño).

29d) Es como muy tonto.

29e) Se reveló en medio de su joven generación como un auténtico rebelde.

29f) Como plato fuerte, ofrecían un descenso por el río Sella.

Finalmente, hay enunciados ambiguos:

13 Aqú el consecuente puede verse como una proposición parafraseable en estos términos: "[del mismo modo que] es un mar en calma". Pero como el antecedente, que está explícito, es un adjetivo podria pensarse en otra posibilidad: “[semejantes a] un mar en calma". Con ello, la construcción de como guardaria con su antecedente y núcleo una homogeneidad estructural, ya que actúa como complemento de un predicativo. 
30) Lo detuvieron como a un terrorista.

que puede verse como "lo detuvieron de forma semejante a como se detiene a los terroristas" o como "la detención fue debida a que se le tomó por un terrorista".

El resumen de este rápido vistazo es que no parece que el consecuente introducido por como deba poseer en todos los casos estatuto proposicional, en contra de una arraigada creencia existente (cf. Cano 1995: 93). Y si quiere seguirse por este camino, hay que pedir a partidarios, y detractores, una teoria clara y bien definida de la elipsis.

3. CONCLUSIONES: EVALUACIÓN DE LA TEORIA DEL SIGNIFICADO BÁSICO DE COMO

En efecto, como es una forma llena de problematicidad y, por eso mismo, un excelente banco de prueblas de la teoría del significado básico, constante y unitario. Los estudiosos del como destacan su tendencia a la diversificación. Uno de ellos reconoce que:

Es la particula española que con mayor facilidad puede introducir segmentos oracionales y no oracionales; puede funcionar sola, o formando parte de varias correlaciones, o bien apoyándose en otros elementos de la oración en la que se integra (Cano 1995: 11-2).

L. Santos Río (1994: 168, n. 8) habla de la frecuencia con que como es el elemento marcado en muchos de sus usos (modal-comparativo, condicional, causal, completivo...).

Todo esto es verdad, pero también que siempre es posible, con mayor o menor violencia, reducir la aparición de como a una constante. Sobre esta violencia, conviene tener en cuenta algo que está muy claro en cualquier campo científico desde el establecimiento en física cuántica de los principios de indeterminación (Heisenberg) y complementariedad (Bohr): la intervención siempre del investigador. Pese a la restricción referida a los casos de antecedente "global y envuelto" (2.2.); en el caso de la teoría de la unitariedad de como, esta supone un desglose, una división -entre el antecedente ASI y como- de algo que normalmente, por la ausencia del antecedente, aparece unido en la lengua, representado sólo por como. Esta actuación del estudioso se produce en aras a una mejor explicación, pero el resultado es una alteración de la realidad inmediata.

Aunque algún análisis haga fácil la acusación de apriorismo (Cano 1995: 12 n. 4), este modo de actuar —que se da en toda teoría - no implica obliga- 
toriamente falsedad, la realidad es sumamente compleja y presenta diversos estratos. Ahora, el que no implique obligatoriamente falsedad no supone tampoco certeza declarada. La suposición del significado unitario, como sus opuestas, son de esas hipótesis metafísicas, que están en los fundamentos de las teorras científicas y que poseen un carácter muy poco falsable. Cuentan con sus argumentos favorables pero con sus dificultades en el terreno más directo de los hechos. Si no fuera asi, no entraría en la cabeza que existiese las posiciones contrarias.

¿Qué hacer? ¿Qué pensar entonces? Pues, permítasenos dos consejos. El primero, recordar el hecho básico, que afecta a todos los elementos del sistema lingǘrtico, de su tendencia a la desmotivación, a la opacidad, con la consecuencia del ensanchamiento de sus márgenes de uso. Ya Hockett, explicando los cambios que experimentan los sonidos, señaló cómo las pronunciaciones van alejándose del ideal originario confiadas en la colaboración del oyente (Hockett 1958: 423-427). Realidad del funcionamiento de las lenguas que encuentra una buena explicación en los principios, establecidos por J. Verschueren, de negociación (infra 1.2.3.), adaptación y variabilidad (cf. Bertuccelli Papi 1993: 105-113).

Estas nociones generales encajan perfectamente en el caso que nos ocupa. Referente y construcción con como conforman un segmento que, genéricamente, puede considerarse de carácter modal, en el que la segunda aparece como un complemento normalmente no restrictivo de su antecedente. Sin embargo, como se utiliza en muchos y variados contextos, y en aquellos - sujetos a menudo más al orden pragmático-discursivo que al estrictamente gramaticalen los que se dan fenómenos como la anteposición de la construcción de como, dificultades de recuperación del antecedente, la presencia de antecedentes no estrictamente modales (por ejemplo, tanto), se diluye el carácter modal de la construcción de como, derivada de su condición de complemento del antecedente modal.

Éste es el origen de esos valores no modales (condicional, causal, temporal, relativo ...) de las construccionés de como, señalados por numerosos gramáticos y que acarrean al mismo tiempo el cuestionamiento de su condición de conector relativo-adverbial. Es una dificultad grave para la teoría unitaria de como; no obstante, no puede negársele, en la mayoría de los casos, que conserva un cierto carácter mostrativo anafórico, un valor modal, en sentido amplio, y los contenidos relacionales de "identidad" o "analogía". Desde una perspectiva prototípica, podría decirse que, en los ejemplos periféricos, sólo alguna de estas notas se da.

El segundo consejo que nos permitimos dar es metodológico: se avanza dejando la estéril escolástica y pasando a los hechos. Al recordar esta obvie- 
dad, nos viene a al memoria también la invitación de Wittgenstein a volver a la sencillez, a los ejemplos elementales del lenguaje infantil y primitivo, caracterizados por la libertad con que se emplean. Esta invitación es quizá excesiva, pues el uso lingüístico no se reduce a estas muestras, pero tiene la virtud de recordarnos la libertad con la que se mueve la creatividad linguística y cómo no puede aherrojarse ésta en los rígidos esquemas teóricos.

\section{Biblografía}

ACERo, J.J. (1993): Lenguaje y filosofia, Barcelona: Octaedro.

Alarcos LloRACH, E. (1994): Gramática de la lengua española, Madrid: EspasaCalpe.

Alcina Franch, J. \& Blecua, J.M. (1975): Gramática española, Barcelona: Ariel. BELINCHÓN, M. \& IGOA, J.M. \& RIVIĖRE, A. (1992): Psicología del lenguaje. Investigación y teoría, Madrid: Trotta ${ }^{2}, 1994$.

BeLlo, A. (1848/1860): Gramática de la lengua castellana (ed. crítica de Ramón Trujillo), Sta. Cruz de Tenerife: Inst. de Filología «Andres Bello», 1980.

BertucCelli PAPI, M. (1993): Qué es la pragmática, Barcelona: Paidós, 1996.

CANo, R. (1988): «Coordinación y subordinación: "como" en español medieval», en M. Ariza et al. (eds.): Actas del I Congreso Int. de Historia de la Lengua Española, I, Madrid: Arco/Libros, 301-317.

-. (1995): Sintaxis histórica de la comparación en español. La historia de COMO, Sevilla: Universidad de Sevilla.

COSERIU, E. (1973): Lecciones de linguística general, Madrid: Gredos, 1981.

- (1989): «Principes de syntaxe fonctionnellew, Travaux de Linguistique et Philologie XXVII, 5-46.

-. (1990): «Semántica estructural y semántica cognitiva*, en Profesor Francisco MarsáJJornadas de Filología, Barcelona: Universitat de Barcelona, 239-282.

EsCANDELl, M.' V. (1993): Introducción a la pragmática, Barcelona: Anthropos/UNED.

FERRARI, A. (1995): Connessioni (Uno studio della subordinazione avverbiale), Gehève: Slatkine.

FUENTES, C. (1996): Aproximación a la estructura del texto, Málaga: Ágora.

Garcfa, E. C. (1992): «Por qué como o porque», Nueva Revista de Filología Hispánica XL.2., 599-621.

GARRIDO MEDINA, J. (1991): «Enlaces intraoracionales: Composicionalidad e interpretación», en C. Martín Vide (ed.): Lenguajes naturales y lenguajes formales (VI.2), Barcelona: PPU, 581-599.

Gosselin, L. (1990): «Les circonstanciels: de la phrase au texte», Langue Francaise (mai 1990), 37-45. 
GUTIÉRREZ ORDÓNEZZ, S. (1986): Variaciones sobre la Atribución, León: Univ.

-. (1994): «Estructuras ecuandicionales», en V. Demonte (ed.): Gramática del españal, México: El Colegio de México (Publicaciones de la Nueva Revista de Filologia Hispánica VI), 363-383.

- (1995): «Referencia y pronominalización de dicto», Comunicación (resumen) presentada al XXV Simposio de la Sociedad Española de Linguística (Zaragoza, 11/14-dic.-1995).

HALLIDAY, M.A.K. (1985/1994): An introduction to Functional Grammar, London: E. Arnold ${ }^{2}$.

HERnÁNDEZ PARICIO, F. (1992): «Sobre las relaciones interclausales», Verba 19, 129 176.

HockETt, Ch. F. (1958): Curso de lingüística moderna, trad. esp., B. Aires, EUDE$\mathrm{BA}^{4}, 1979$.

Kuno, S. \& Takami, K-I. (1993): Grammar and Discourse Principles, Chicago: The Univ. of Chicago Press.

LE Goffic, P. (1993): Grammaire de la Phrase Franfaise, Paris: Hachette.

LOPEZ GARCtA, P. (1994): Gramática del español (I. La oración compuesta), Madrid: Arco/Libros.

MaIngueneau, D. (1976): Introducción a los métodos del análisis del discurso, trad. esp., B. Aires: Hachette.

MARTf SANCHEZ, M. (1993): «El complemento circunstancial y los complementos circunstanciales», Anuario de Estudios Filológicos XIV, 263-274.

MARTín Rojo, L. \& MeEuwis, M. (1993): «Referentes al sujeto pronominales y tácitos en la conversación en español: un enfoque pragmáticon, en $\mathrm{H}$. Haverkate et al. (eds.): Aproximaciones pragmalinguísticas al español (Diálogos Hispánicos $n^{\circ}$ 12), Amsterdam-Atlanta: Rodopi, 87-118.

Masia Canuto, M.* L. (1994): El complemento circunstancial en español, Castello: Univ. Jaume I.

MoREno AYORA, A. (1991): Sintaxis y semántica de "como", Málaga: Ágora.

MORENo CABRERA, J. C. (1994): Curso universitario de lingüística general (II), Madrid: Síntesis.

MoRerA, M. (1990): «El adverbio relativo "como": significado y usos», en M." Á. Álvarez Martínez (ed.): Actas del Congreso del XX $X^{\circ}$ Aniversario de la SEL, Madrid: Grados, 681-691.

NARBONA, A. (1989): Las subordinadas adverbiales impropias en español (Bases para su estudio), Málaga: Ágora.

-. (1990): Las subordinadas adverbiales impropias en español (II) Causales y finales, comparativas y consecutivas, condicionales y concesivas, Málaga: Ágora.

PARRET, H. (1991): «Sens homogéne et sens hétérogène: Les domaines de la sémantique et de la pragmatique», Histoire Epistémologie Langage 13/1, 133-150. 
POTTIER, B. (1962): Systèmatique des éléments de relation, Paris: Klincksieck.

PRIETO DE LOS Mozos, E. (1994): «Reglas y funciones del discurso», en A. Alonso et al. (eds.): Il Encuentro de lingüistas y filólogos de España y México, Salamanca: J." de Castilla y León, 509-525.

Ramón Trives, E. (1982): Estudios Sintáctico-Semánticos del Español -I L La Dinámica Oracional, Murcia: Godoy.

Rojo, G. \& JiMÉNEZ JULIÁ, T. (1989): Fundamentos del análisis sintáctico funcional, Santiago: Univ.

SÁNCHEZ LOPEZ, C. (1995): «Construcciones concesivas con para», RSEL 25.1., 99123.

SÁNCHEZ SALOR, E. (1993): Semántica y sintaxis. La oración compuesta latina, Salamanca: Universidad de Extremadura.

SANCHO CREMADES, P. (1994): Les preposicions en català, Valencia: LynX Annexa 7.

SANTOS Rfo, L. (1994): «Lexicografía elemental: Un aspecto del diccionario academico", en A. Alonso et al. (eds.): II Encuentro de Lingüistas y Filologos de Es. paña y México, Salamanca: J." de Castilla y León, 165-204.

TORRego, E. (1994): “Cómo», en V. Demonte (ed.): Gramática del español, México: El Colegio de México (Publicaciones de la Nueva Revista de Filología Hispánica VI), 255-266.

TRUillo, R. (1976): Elementos de semántica lingüística, Madrid: Cátedra.

- (1988): Introducción a la semántica española, Madrid, Arco/Libros.

- (1990): «Sobre la explicación de algunas construcciones de como», Verba 17, 249-266.

UribeetXebarria, T. (1992): Palabras y lengua, Bilbao: Univ. del País Vasco.

VANDERLYNDEN, A-M. (1992/4): «A propos de la valeur "e/a(n)nonciative" du relateur como», en Recherches en Linguistique Hispanique (Actes du Colloque d'Aix-en-Provence, 20, 21/3/1992), sous la dir. de J. Stolidi, Aix-en-Provence, Publ. de la Univ. de Provence, 1994, 431-440. 